OPEN ACCESS

Edited by:

Anna Maria Lavezzi,

Università degli Studi

di Milano, Italy

Reviewed by:

Roquyya Gul,

University of Lahore, Pakistan

Beatrice Paradiso,

University of Padua, Italy

*Correspondence:

Riffat Mehboob

riffatmehboob@kemu.edu.pk,

mehboob.riffat@gmail.com

Specialty section: This article was submitted

to Neuropediatrics, a section of the journal

Frontiers in Neurology

Received: 24 January 2017 Accepted: 19 June 2017

Published: 06 July 2017

Citation:

Mehboob R, Kabir M, Ahmed N and Ahmad FJ (2017) Towards Better

Understanding of the Pathogenesis of Neuronal Respiratory Network in Sudden Perinatal Death.

Front. Neurol. 8:320.

doi: 10.3389/fneur.2017.00320

\section{Towards Better Understanding of the Pathogenesis of Neuronal Respiratory Network in Sudden Perinatal Death}

\author{
Riffat Mehboob ${ }^{1,2 *}$, Mahvish Kabir ${ }^{3}$, Naseer Ahmed ${ }^{4,5}$ and Fridoon Jawad Ahmad ${ }^{1}$ \\ ${ }^{1}$ Biomedical Sciences, King Edward Medical University, Lahore, Pakistan, ${ }^{2}$ Faculty of Allied Health Sciences, University of \\ Lahore, Lahore, Pakistan, ${ }^{3}$ Department of Chemistry, School of Science, University of Management and Technology (UMT), \\ Lahore, Pakistan, ${ }^{4}$ Department of Cardiac Surgery, University of Verona Medical School, Verona, Italy, ${ }^{5}$ Section of \\ Pharmacology, University of Verona Medical School, Verona, Italy
}

Sudden perinatal death that includes the victims of sudden infant death syndrome, sudden intrauterine death syndrome, and stillbirth are heartbreaking events in the life of parents. Most of the studies about sudden perinatal death were reported from Italy, highlighting two main etiological factors: prone sleeping position and smoking. Other probable contributory factors are prematurity, male gender, lack of breastfeeding, respiratory tract infections, use of pacifiers, infant botulism, extensive use of pesticides and insecticides, etc. However, extensive studies across the world are required to establish the role of these factors in a different subset of populations. Previous studies confirmed the widely accepted hypothesis that neuropathology of the brainstem is one of the main cause of sudden perinatal death. This study is an effort to summarize the neuropathological evaluation of the brainstems and their association to sudden perinatal death. Brainstem nuclei in vulnerable infants undergo certain changes that may alter the sleep arousal cycle, cardiorespiratory control, and ultimately culminate in death. This review focuses on the roles of different brainstem nuclei, their pathologies, and the established facts in this regard in terms of it's link to such deaths. This study will also help to understand the role of brainstem nuclei in controlling the cardiorespiratory cycles in sudden perinatal death and may provide a better understanding to resolve the mystery of these deaths in future. It is also found that a global initiative to deal with perinatal death is required to facilitate the diagnosis and prevention in developed and as well as developing countries.

Keywords: sudden infant death, sudden fetal death, sudden perinatal death, sudden intrauterine death, stillbirth, neuropathology

\section{INTRODUCTION}

Sudden perinatal mortalities include sudden fetal death or Sudden Intrauterine Death Syndrome (SIUDS), stillbirths, and Sudden Infant Death Syndrome (SIDS) due to some unknown reason. Stillbirth is death of a fetus after 20 weeks of gestation, weighing 350-1,000 g (1). The annual global incidence of stillbirths is 2.7 billion, with $15-35 \%$ more deaths in developing countries, which is very alarming $(2,3)$. SIDS also termed as "Crib death" or "Cot death" is defined as the sudden and inexplicable death of an apparently healthy newborn or infant who dies before the first birthday and reason remains a mystery even after a complete autopsy or thorough investigation (4). To find out the 
exact cause of death in SIDS or SIUDS, victims are a major diagnostic challenge. SIUDS are broadly categorized as accidental and non-accidental mortalities (5). It was found that victims of sudden perinatal deaths usually belong to economically poor family and incidence is high in winter, during midnight and weekends (6-8). Many other risk factors were also observed in the SIDS victims such as male gender (9), ethnicity (10), and deformational plagiocephaly (11). Some maternal factors reported were maternal age (12), obesity (13), and smoking during pregnancy (14), whereas environmental factors were prone sleeping position (15), soft bedding, over heating (16), lack of breastfeeding (17), and higher latitudes (18). More recently, some new theories have been proposed, and it was highlighted that infant gut microbiome may modulate the brainstem serotonergic system and may serve as a new possible risk factor for causing SIDS (19). Latest theories like SIDS-critical diaphragm failure hypothesis suggest that the critical diaphragm failure during pregnancy may end up in SIDS by cessation of breathing (15), whereas substance P-neurokinin 1 hypothesis suggests a possible involvement of this tachykinin peptide in sudden perinatal deaths by modulating the cardiorespiratory control (20).

The causes of these unexplained deaths can be environmental, genetic or congenital, etc. So far, the most accepted hypothesis to define SIDS is triple-risk model of Filiano and Kinney (21), in which the infants exposed to external stress, and have some intrinsic vulnerability will be at higher risk of having neurological and developmental abnormalities that can result in SIDS (22). The National Institute of Child Health and Development SIDS Strategic Plan 2000 states that "SIDS is a developmental disorder. It's origins are during fetal development" (23). Subtle hippocampus abnormalities, seizures, malfunctioning in central nervous system mechanisms, abnormalities in neurotransmitter secretions, and in the nuclei of brainstem cells are also suggested as causes of SIDS (24).

\section{NEUROPATHOLOGY OF SUDDEN PERINATAL DEATH}

Neuropathology deals with the diseases of the nervous system tissue, either through small surgical biopsies or whole-body autopsies. Neuropathological studies include anatomy, pathology, neurology, and neurosurgery (4). In this study, the main focus is on summarizing the neuropathological anomalies of sudden fetal deaths, stillbirths, and infant mortalities due to alterations in neurotransmitter's release and nuclei of brainstem neuronal centers. The human cerebellar cortex development involves rapid transformations, thickness, as well as the reorganization of cortical layers in the fetal and early postnatal stages (25). Any change due to mutations, epigenetic and environmental factors such as smoking, hypoxia, pesticide exposure, and infection can result in neuropathological conditions. Even though current studies are unable to pin point the causes but brainstem abnormalities that are responsible for respiration and responses to asphyxia, especially in the sleep and arousal, are thought to be the probable causes $(26,27)$. Defects in brainstem neural circuits involved in cardiorespiratory regulation may be one of the leading causes of SIDS (28).

\section{BRAINSTEM CONTROL OF RESPIRATION DURING THE TRANSITION FROM WATER TO AIR BREATHING}

Breathing rhythm in fetus begins at the 10th week of gestation (29) which changes from irregular to a regular pattern at the time of birth by unknown mechanisms. In the neonatal period, a regular respiratory rhythm (RR) and cardiorespiratory coupling is controlled by neuronal centers in the brainstem (30). These RRs are controlled by several pathways in the neuronal networks, e.g., pre-Botzinger complex and the Kölliker-Fuse as well as some cortical and cerebellar networks (31). These pathways are also involved in involuntary functions, sleep-awake cycle, and upper respiratory tract reflexes. It is found that brain-derived neurotrophic factor (BDNF) is involved in steady rhythm generation.

In response to stress such as hypoxia, these networks are able to reconfigure, to generate multiple breathing patterns, and to facilitate autoresuscitation. There are vital changes in caudal serotonergic (5-HT) system at the end of the fetal period and the start of the neonatal period that are regulated by neuronal networks. Serotonin (5-HT) receptor binding is gradually decreased as the gestation progresses.

Instability in the early control of breathing is proportional to frequency of apnea in infants. Brief apneic spells are common within the first few minutes after birth, later on more prolonged episodes of apnea are observed. These apneic episodes (breath holding) are associated with prematurity, laryngeal chemoreflex activity or bradycardia, and loss of muscle tone ("near-miss SIDS" or apparent life-threatening events) (32). Episodic apnea and bradycardia have been observed in the infants who died of SIDS (33). Vulnerable infants with immature neuronal centers are unable to face the life-threatening challenges such as hypoxia and hypercapnia during sleep, which may lead to imbalances in serotonergic networks (34). Consequently, abnormality in specific brainstem neuronal networks have been observed in SIDS that cause failure of these reflex responses to arousal.

\section{Pontine Kölliker-Fuse Nucleus (KFN)}

Studies established the role of pontine KFN (Figure 1; Table 1) in breathing control; it is interconnected with the prevalent serotonin and noradrenaline neurons in the brainstem. It is suggested that orexin has a strong effect on the brainstem raphe nuclei (RN) and locus coeruleus, in arousal from sleep (35). The neurobiological functions of these stem cell nuclei are closely linked to the breathing modifications (36). As KFN is a main component of the orexin system that is involved in arousal, KFN was observed to play a key role in providing a breathing rhythm and coordination of sleep-to-wake transition. Any defect in orexin expression in $\mathrm{KFN}$ is responsible for prevention of arousal and can be a crucial factor in causing SIDS (36).

Experimental studies indicate that the neurotrophin BDNF has a vital role in the central respiratory network development to sustain life. In the prenatal and postnatal breathing circuit, pontine KFN is a fundamental component (54). BDNF pathway dysfunctions may possibly distort the normal KFN development 


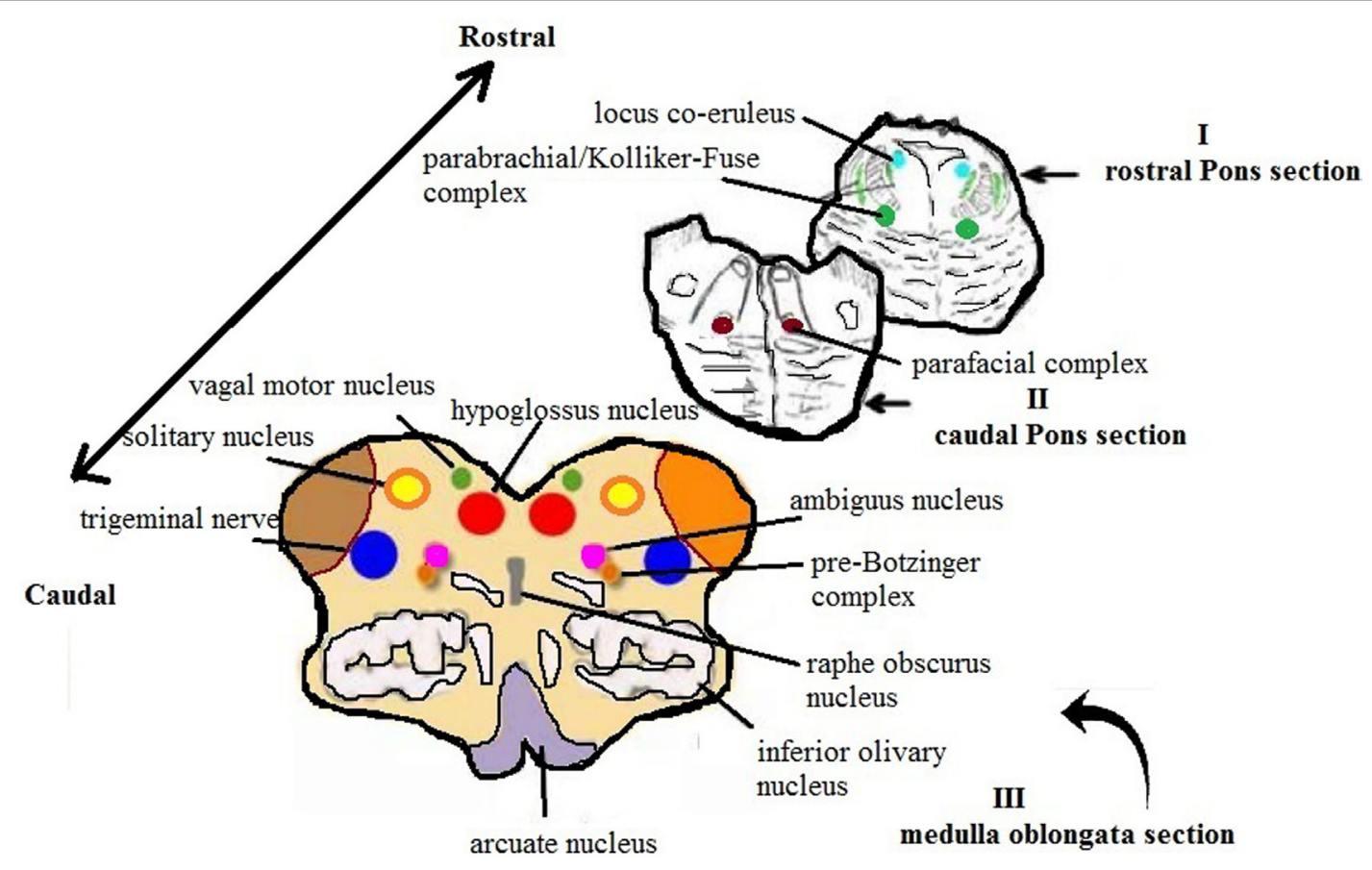

FIGURE 1 | Schematic representation of the main histological sections obtained from the brainstem for the anatomopathological examination [modified image adapted from Matturri et al. (31)].

in SIUDS and SIDS victims by interfering with the breathing control. Alterations in the BDNF expression in KFN have been observed in many respiratory diseases in human such as the Rett's and the congenital central hypoventilation syndromes (37).

\section{Inferior Colliculus Nucleus}

Developmental defects of hearing pathways involve defects in the specific brainstem centers, specifically in the cochlear, vestibular, superior olivary, and inferior olivary complex (Figure 1). Significantly, more alterations were observed in cytoarchitecture of auditory and respiratory networks of SIDS cases as compared to controls in one study (26). The inferior colliculus has a vital role in the processing of acoustic information. It is believed that neuromodulator serotonin concentration can be a factor in sudden unexplained fetal and infant death syndromes. Weak serotonin positivity was observed in a study conducted on brainstems of SIDS and SIUDS victims, indicative of functional abnormality of inferior colliculus. Hypoplasia or anomalies in the associated structures, e.g., RN and the superior olivary complex was also observed in the fetus of smoking mothers (Table 1). A role of inferior colliculus in breathing apart from hearing was also suggested (38).

\section{Locus Coeruleus Complex}

Locus coeruleus complex (Figure 1; Table 1) is a part of the brainstem in pons mainly responsible for the physiological responses to conditions of stress and panic. It is the main region that produces norepinephrine (noradrenaline), tyrosine hydroxylase, and neuromelanin (NM) (55). A strong correlation between defects in noradrenaline system, low levels of NM, hypoplasia, along with a high neuronal death rate, were found mainly in the locus coeruleus complex of fetal and infant sudden death victims (44). Studies have shown that locus coeruleus complex is involved in vital activities related to the brain interconnections and behavioral adjustments, including coordination of the sleep-wake cycle and control of the cardiorespiratory functions (56).

\section{Superior Olivary Complex}

The superior olivary complex (Figure 1; Table 1) is a group of brainstem nuclei that have multiple roles in hearing and is involved in ascending and descending auditory pathways (57). Irregular cytoarchitectural patterns like hypoplasia/agenesis, immature hypercellularity, and dysgenesis of contiguous structures involved in breathing circuit in medial superior olivary nucleus were reported in a study, and it was proposed that this nucleus had influence on all the vital activities along with hearing (45).

\section{Retrotrapezoid Nucleus (RTN)}

The RTN is part of caudal pons and comprises cluster of glutamatergic and non-aminergic neurons that are responsible for the homeodomain transcription factor Phox $2 \mathrm{~b}$ (a transcriptional factor involved in congenital central hypoventilation syndrome) expression (58). Immunohistochemical expression of Phox $2 b$ neurons inside the caudal pons points out the developmental abnormalities of the human RTN (Table 1). It may acutely affect the chemoreception control, thus, performing a vital part in the pathogenesis of SIUDS and SIDS (46).

\section{Spinal Trigeminal Nucleus (STrN)}

The STrN (Figure 2; Table 1) is part of medulla, and it transmits information related to pain and temperature in the orofacial 
TABLE 1 | Summary of studies on brainstem nuclei along with their physiological and pathological roles (+ indicate increase and - is decrease in expression).

\begin{tabular}{|c|c|c|c|c|c|c|c|}
\hline Nucleus & Brain area & Role of nucleus & Neurotransmitter & Expression & Alteration in function & Possible cause & Reference \\
\hline KFN & $\begin{array}{l}\text { Rostral PONS, } \\
\text { brainstem }\end{array}$ & $\begin{array}{l}\text { Arousal/sleep breathing control in } \\
\text { perinatal life, synaptic plasticity }\end{array}$ & OR, BDNF & - & $\begin{array}{l}\text { Fetal inhibitory reflex arrest breathing, deranged normal } \\
\text { KFN development, and loss of breathing control }\end{array}$ & Hypoxic conditions, smoking & $(36,37)$ \\
\hline ICN & Mesencephalon & Acoustic processing & $5-\mathrm{HT}$ & - & Dysgenesis of RN, superior ON, ICN & Nicotinic absorption, smoking & $(26,38)$ \\
\hline Nucleolus & Brainstem & Ribosomal synthesis & AgNOR & - & PC degeneration, disturbed cardiac cycle & Nicotinic absorption, smoking & (39) \\
\hline AP & Fourth ventricle & Controls vomiting & - & - & AP lesion & Insecticide & (40) \\
\hline $\begin{array}{l}\text { LC, KFN, CAN, RN, } \\
\text { pre-BotC, PF/FC }\end{array}$ & Cerebral cortex & $\begin{array}{l}\text { Breathing control, sleep-awake } \\
\text { cycle }\end{array}$ & $\alpha 7-N A c R$ & + & Hypoplasia of all nuclei & Smoking, insecticide & $(14,41)$ \\
\hline POD & Cerebellar Purkinje & $\mathrm{RR}$ & $\alpha 7-N A c R$ & & Alterations of POD network & Smoking & (42) \\
\hline NN & Brainstem & Mitotic cycle & NeuN & - & Cell death increased, neuronal immaturity & Smoking & (43) \\
\hline LC & Brainstem & $\begin{array}{l}\text { Sleep-wake cycle, control } \\
\text { of CRS }\end{array}$ & TK, NM, TH & - & $\begin{array}{l}\text { NM, hypoplasia, neuronal death, alterations of } \\
\text { noradrenaline system, low neuromelanin, neuronal death }\end{array}$ & Smoking & (44) \\
\hline soc & Brainstem & Acoustic information & - & - & $\begin{array}{l}\text { Hypoplasia of ON, RTN, FN, hypercellularity, dysgenesis } \\
\text { of structures related to RR, alterations in auditory, and } \\
\text { respiratory network }\end{array}$ & Smoking & $(26,45)$ \\
\hline RTN & Caudal pons & Breathing, chemoreception & PHOX2B & - & Developmental abnormalities in RTN & Smoking & (46) \\
\hline AP & $\begin{array}{l}\text { Brainstem, fourth } \\
\text { ventricle choroid plexus }\end{array}$ & $\begin{array}{l}\text { Autonomic control of cardiac and } \\
\text { respiratory activity }\end{array}$ & - & - & $\begin{array}{l}\text { Lack of vascularization, hypoplasia, cystic formations, } \\
\text { reactive gliosis }\end{array}$ & Smoking & $(47)$ \\
\hline STrN & Brainstem & Pain, thermofluctuations, RR & SP & -+ & Pre-BtzC, RN, and AN hypoplasia & Smoking & (48) \\
\hline IMN & Brainstem & Breathing activity & - & - & Hypoplasia, neuronal immaturity & Smoking & (49) \\
\hline G-Mt & Brainstem & $\begin{array}{l}\text { Modulation of spinal cord motor } \\
\text { activity }\end{array}$ & - & - & Hypoplasia, apoptosis & Smoking & (50) \\
\hline HGN & Brainstem & $\begin{array}{l}\text { Swallowing, chewing, vocalization, } \\
\text { inspiration }\end{array}$ & SM & + & Hypoplasia, hyperplasia, no interneurons & Smoking & (51) \\
\hline $\mathrm{RN}$ & Brainstem & Sleep-wake cycle & 5-HTT & - & Hypoplasia & Smoking & (52) \\
\hline Pre-BotC & Medulla & $\mathrm{RR}$ & NK1R, SM & - & $\begin{array}{l}\text { Hypoplasia, low neuronal no., dendritic } \\
\text { hypodevelopment }\end{array}$ & Smoking & (53) \\
\hline
\end{tabular}

OR, orexin receptor; BDNF, brain-derived neurotrophic factor; 5-HT, serotonin; AP, area prostrema; RTN, retrotrapezoid nucleus; ON, olivary nucleus; LC, locus coerulius; STrN, spinal trigeminal nucleus; KFN, Köliker-Fuse nucleus; ICN, inferior collicus nucleus; RN, raphe nucleus; AN, arcuate nucleus; PF/FC, parafacial/facial complex; pre-BotC, pre-Bötzinger; IMN, intermediolateral nucleus; G-Mt, Guillain-Mollaret triangle (dentato-rubro-olivary network); HGN, hypoglossal nucleus; $\alpha 7-N a c R, \alpha 7-$ nicotinic acetylcholine receptor; TK, tyrosine kinase; NM, neuromelanin; CRS, cardiorespiratory system; RR, respiratory rhythm; TH, tyrosine hydroxylase; NN, nucleus of neurons; POD, Purkinjeolivo-dentate network; SM, somatostatin; 5-HTT, serotonin transporter; NK1R, neurokinin 1 receptor. 


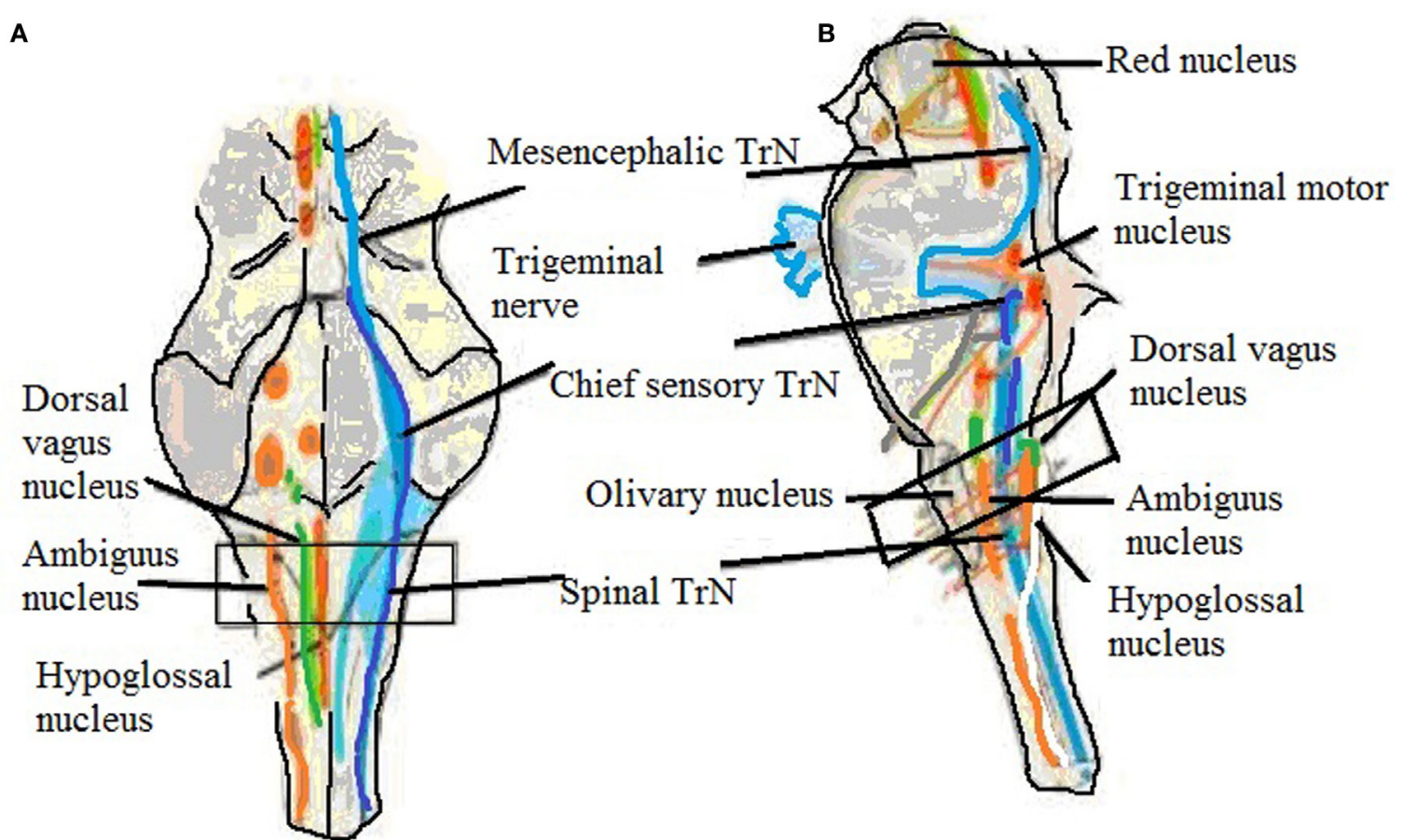

FIGURE 2 | Brainstem showing trigeminal nucleus and also shows the level of sampling. (A) Ventral view and (B) side view showing trigeminal nerve, mesencephalic, chief sensory, and spinal trigeminal nucleus (60).

region. The cranial nerves transmit pain stimuli from peripheral regions to the STrN (59). A reduced SP expression levels in the fibers of STrN in SIDS victims and higher levels in SIUDS victims were observed $(20,48)$.

\section{Intermediolateral Nucleus (IMN)}

In the brain, the sympathetic preganglionic neurons reside in the IMN that is a part of spinal cord. These are groups of columnar cells organized longitudinally, in the gray matter of the lateral horn. These cells are present between the first thoracic spinal region and the third lumbar region (61). Experimental studies have demonstrated the role of IMN in the breathing activities and development of a spinal cord-brainstem network (62). In SIDS, IMN fails to mature progressively; it's neurons do not transform from a round to a polygonal shape with extended axons and drastically decrease in number. In unexplained fetal and infant death victims, hypodevelopment of IMN such as neuronal immaturity in a normal structure, hypoplasia, and agenesis was seen (49) (Table 1).

\section{Guillain-Mollaret Triangle (G-Mt) (Dentato-Rubro-Olivary Network)}

The G-Mt (Figure 3; Table 1) has three parts: the ipsilateral red nucleus, the inferior olive, and the contralateral dentate nucleus in the midbrain, medulla, and cerebellum to form dentatorubro-olivary pathway (63). G-Mt is known to be involved in the pathogenetic mechanisms of the palatal myoclonus, in SIDS and SIUDS. A significant increase of lesions of these three nuclei were found in SIDS victims (50).

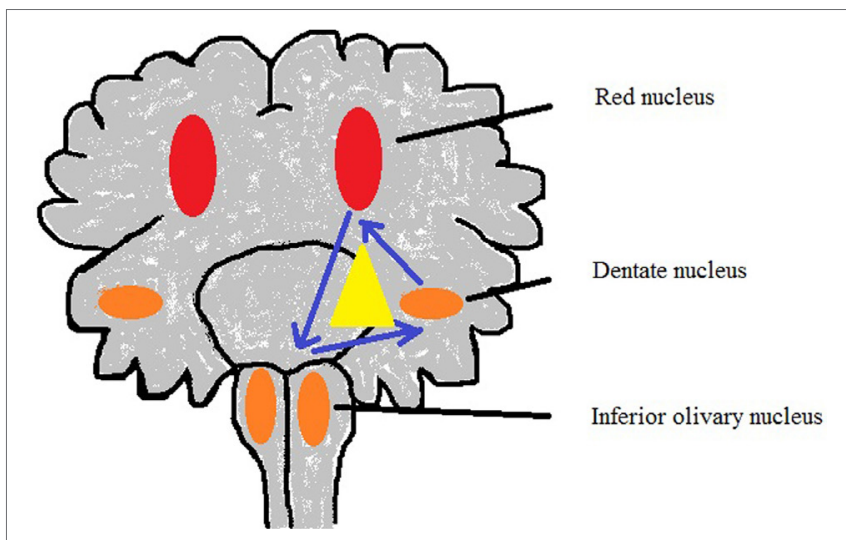

FIGURE 3 | Sketch of Guillain-Mollaret triangle derived from Lavezzi et al. (50)

\section{Medullary Hypoglossal Nucleus (HGN)}

The hypoglossal nerve is a motor nerve that controls extrinsic and intrinsic muscles of the tongue. It arises from the HGN (Figure 1; Table 1) in the brain stem and controls swallowing, chewing, vocalization, and inspiration (64). HGN anomalies such as hypo/ hyperplasia, somatostatin positivity, and absence of interneurons were evident in SIDS cases (51). Unlike to the trigeminal nucleus, $\mathrm{HGN}$ is not considered as a main respiratory regulatory center, yet, it contains motoneurons with respiratory-related rhythmical discharges. Primarily, HGN controls the genioglossus, an extrinsic muscle of the tongue, which plays a significant role in regulating a patent airway during inspiration $(65,66)$. 


\section{Raphe Nuclei}

The RN (Figure 1; Table 1) are medial part of the reticular formation that forms a crest of cells in the center and in the medial portion of the brainstem (67). In a study, cytoarchitecture and the localization of human $\mathrm{RN}$ in the brainstem were done to analyze the association of raphe nucleus pathology and serotonin transporter gene (5-HTT) polymorphisms. It was also suggested that SIUDS should not be viewed separately from SIDS, due to potentially shared neuropathological and genetic grounds (52).

\section{Pre-Bötzinger Complex (Pre-BötC)}

In the ventrolateral medulla of the brainstem, a cluster of interneurons is present known as pre-BötC (Figure 1; Table 1). It is believed that it has a vital role in the generation of RR in humans (68). Neuropathology of the pre-BötC, altered neurokinin 1 receptors, and somatostatin expression were observed in a subset of SIDS and SIUDS victims as compared to the controls. Hypoplasia with a low neuronal number with dendritic hypodevelopment, defective neuronal morphology, immunonegativity of neurotransmitters, and agenesis was sighted. These abnormalities are directly linked with the neonatal deaths and still births (53).

In most of these studies, an association has been found with maternal smoking. Nicotine is one of the few lipid-soluble substances that are able to go beyond the blood-brain barrier (69) and act directly on the expression of genes that control the developing brain. Therefore, among the numerous compounds present in cigarette smoke, carbon monoxide and nicotine could affect the fetal brain through indirect or direct action (70). As there are not many studies conducted on SIDS and SIUDS worldwide and it is multifactorial, so we cannot conclude concretely, that only smoking is the main etiological factor. Recently, some studies have been done on the role of pesticides and insecticides in these sudden deaths and an association has been observed $(41,71)$. Most of these studies were conducted mainly in Italy, so there is a need to explore the risk factors in other parts of

\section{REFERENCES}

1. Nguyen RH, Wilcox AJ. Terms in reproductive and perinatal epidemiology: 2. Perinatal terms. J Epidemiol Community Health (2005) 59(12):1019-21. doi:10.1136/jech.2004.023465

2. Jehan I, McClure EM, Salat S, Rizvi S, Pasha O, Harris H, et al. Stillbirths in an urban community in Pakistan. Am J Obstet Gynecol (2007) 197(3):e1-8. doi:10.1016/j.ajog.2007.07.012

3. McClure EM, Saleem S, Pasha O, Goldenberg RL. Stillbirth in developing countries: a review of causes, risk factors and prevention strategies. JMatern Fetal Neonatal Med (2009) 22(3):183-90. doi:10.1080/ 14767050802559129

4. Pusiol T, Morichetti D, Grazia Zorzi M, Matturri L, Lavezzi AM. Sudden intrauterine unexpected fetal death syndrome and sudden infant death syndrome. Iran J Pediatr (2014) 24(4):454-5.

5. Otto-Buckowska E. Sudden infant death syndrome. Pol Merkur Lekarski (2002) 13(78):524-5.

6. Froggatt P, James TN. Sudden unexpected death in infants. Evidence on a lethal cardiac arrhythmia. Ulster Med J (1973) 42(2):136-52.

7. Hodges FB. Sudden infant death syndrome. Calif Med (1972) 116(1):85-6.

8. Peterson DR. Sudden, unexpected death in infants. An epidemiologic study. Am J Epidemiol (1966) 84(3):478-82. doi:10.1093/oxfordjournals.aje. a120660 the world too, e.g., Southeast Asia where infant mortality rate is very high and population is exposed to extra risk factors like consumption of banned insecticides like DDT among others. Moreover, there is no epidemiological data available regarding SIDS and SIUDS in these regions.

\section{CONCLUSION}

Neuropathology in brainstems of SIDS and SIUDS victims are summarized in this study. It is found that several alterations in the brain centers possibly lead to sudden deaths. This updated effort will help in better diagnosis and identification of such cases. Moreover, an association with maternal smoking has been observed in the reported studies. It is noticed that sufficient data to establish all causative factors is not available. So, there is a need to study other dimensions to find out the etiological factors in different populations and different regions of the world. There is an urgent need to expand these studies in other regions of the world, particularly in South East Asia where health-care facilities are very poor and banned agricultural pesticides are still in use.

\section{AUTHOR CONTRIBUTIONS}

RM conceived the idea, planned the review manuscript, made some figures, helped in writing the manuscript, and finalized it. MK gathered already existing literature in the field, made some figures, and helped in writing some parts of manuscript. NA made the table and helped in writing the manuscript. FA finalized the manuscript. All the authors have revised, checked, and approved the final version of the manuscript.

\section{SUPPLEMENTARY MATERIAL}

The Supplementary Material for this article can be found online at http://journal.frontiersin.org/article/10.3389/fneur.2017.00320/ full\#supplementary-material.

9. Mage DT, Donner EM. The fifty percent male excess of infant respiratory mortality. Acta Paediatr (2004) 93(9):1210-5. doi:10.1111/j.1651-2227.2004. tb02751.x

10. Luo ZC, Wilkins R, Platt RW, Kramer MS; Fetal and Infant Health Study Group of the Canadian Perinatal Surveillance System. Risks of adverse pregnancy outcomes among Inuit and North American Indian women in Quebec, 1985-97. Paediatr Perinat Epidemiol (2004) 18(1):40-50. doi:10.1111/j.1365-3016.2003.00529.x

11. Persing J, James H, Swanson J, Kattwinkel J; American Academy of Pediatrics Committee on Practice and Ambulatory Medicine, Section on Plastic Surgery and Section on Neurological Surgery. Prevention and management of positional skull deformities in infants. American Academy of Pediatrics Committee on Practice and Ambulatory Medicine, Section on Plastic Surgery and Section on Neurological Surgery. Pediatrics (2003) 112(1 Pt 1):199-202. doi:10.1542/peds.112.1.199

12. Borhani NO, Rooney PA, Kraus JF. Post-neonatal sudden unexplained death in a California community. Calif Med (1973) 118(5):12-6.

13. Gunther $M$. The neonate's immunity gap, breast feeding and cot death. Lancet (1975) 1(7904):441-2. doi:10.1016/S0140-6736(75)91504-4

14. Lavezzi AM, Ferrero S, Matturri L, Roncati L, Pusiol T. Developmental neuropathology of brainstem respiratory centers in unexplained stillbirth: what's the meaning? Int J Dev Neurosci (2016) 53:99-106. doi:10.1016/j. ijdevneu.2016.06.007 
15. Siren PM. SIDS-CDF hypothesis revisited: cause vs. contributing factors. Front Neurol (2016) 7:244.

16. Blair PS, Mitchell EA, Heckstall-Smith EM, Fleming PJ. Head covering a major modifiable risk factor for sudden infant death syndrome: a systematic review. Arch Dis Child (2008) 93(9):778-83. doi:10.1136/adc.2007.136366

17. Stuebe A. The risks of not breastfeeding for mothers and infants. Rev Obstet Gynecol (2009) 2(4):222-31.

18. Mitchell EA. Risk factors for SIDS. BMJ (2009) 339:b3466. doi:10.1136/bmj. b3466

19. Praveen V, Praveen S. Microbiome-gut-brain axis: a pathway for improving brainstem serotonin homeostasis and successful autoresuscitation in SIDS - a novel hypothesis. Front Pediatr (2017) 4:136. doi:10.3389/fped.2016.00136

20. Mehboob R. Substance P/neurokinin 1 and trigeminal system: a possible link to the pathogenesis in sudden perinatal deaths. Front Neurol (2017) 8(82):1-6. doi:10.3389/fneur.2017.00082

21. Filiano JJ, Kinney HC. A perspective on neuropathologic findings in victims of the sudden infant death syndrome: the triple-risk model. Biol Neonate (1994) 65(3-4):194-7. doi:10.1159/000244052

22. Moon RY, Horne RS, Hauck FR. Sudden infant death syndrome. Lancet (2007) 370(9598):1578-87. doi:10.1016/S0140-6736(07)61662-6

23. Guntheroth WG, Spiers PS. The triple risk hypotheses in sudden infant death syndrome. Pediatrics (2002) 110(5):e64. doi:10.1542/peds.110.5.e64

24. Hoppenbrouwers T. Sudden infant death syndrome, sleep, and seizures. J Child Neurol (2015) 30(7):904-11. doi:10.1177/0883073814549243

25. Matturri L, Lavezzi AM. Unexplained stillbirth versus SIDS: common congenital diseases of the autonomic nervous system - pathology and nosology. Early Hum Dev (2011) 87(3):209-15. doi:10.1016/j.earlhumdev.2010.12.009

26. Lavezzi AM, Ottaviani G, Matturri L. Developmental alterations of the auditory brainstem centers - pathogenetic implications in sudden infant death syndrome. J Neurol Sci (2015) 357(1-2):257-63. doi:10.1016/j.jns.2015.07.050

27. Ozawa Y, Takashima S. Developmental neurotransmitter pathology in the brainstem of sudden infant death syndrome: a review and sleep position. Forensic Sci Int (2002) 130(Suppl):S53-9. doi:10.1016/S0379-0738(02)00139-1

28. Kinney HC, Filiano JJ. Brainstem research in sudden infant death syndrome. Pediatrician (1988) 15(4):240-50.

29. Florido J, Padilla MC, Soto V, Camacho A, Moscoso G, Navarrete L. Photogrammetry of fetal breathing movements during the third trimester of pregnancy: observations in normal and abnormal pregnancies. Ultrasound Obstet Gynecol (2008) 32(4):515-9. doi:10.1002/uog.5329

30. Bratu I, Flageole H, Laberge JM, Kovacs L, Faucher D, Piedboeuf B. Lung function in lambs with diaphragmatic hernia after reversible fetal tracheal occlusion. J Pediatr Surg (2004) 39(10):1524-31. doi:10.1016/j. jpedsurg.2004.06.024

31. Matturri L, Mauri M, Ferrero ME, Lavezzi AM. Unexpected perinatal loss versus Sids - a common neuropathologic entity. Open Neurol J (2008) 2:45-50. doi:10.2174/1874205X00802010045

32. Choi HJ, Kim YH. Apparent life-threatening event in infancy. Korean J Pediatr (2016) 59(9):347-54. doi:10.3345/kjp.2016.59.9.347

33. Kinney HC, Thach BT. The sudden infant death syndrome. N Engl J Med (2009) 361(8):795-805. doi:10.1056/NEJMra0803836

34. Kinney HC, Richerson GB, Dymecki SM, Darnall RA, Nattie EE. The brainstem and serotonin in the sudden infant death syndrome. Annu Rev Pathol (2009) 4:517-50. doi:10.1146/annurev.pathol.4.110807.092322

35. de Lecea L. Optogenetic control of hypocretin (orexin) neurons and arousal circuits. Curr Top Behav Neurosci (2015) 25:367-78. doi:10.1007/7854_2014_364

36. Lavezzi AM. A new theory to explain the underlying pathogenetic mechanism of sudden infant death syndrome. Front Neurol (2015) 6:220. doi:10.3389/ fneur.2015.00220

37. Lavezzi AM, Ferrero S, Roncati L, Matturri L, Pusiol T. Impaired orexin receptor expression in the Kolliker-Fuse nucleus in sudden infant death syndrome: possible involvement of this nucleus in arousal pathophysiology. Neurol Res (2016) 38(8):706-16. doi:10.1080/01616412.2016.1201632

38. Lavezzi AM, Pusiol T, Matturri L. Cytoarchitectural and functional abnormalities of the inferior colliculus in sudden unexplained perinatal death. Medicine (Baltimore) (2015) 94(6):e487. doi:10.1097/MD.0000000000000487

39. Lavezzi AM, Alfonsi G, Pusiol T, Matturri L. Decreased argyrophilic nucleolar organiser region (AgNOR) expression in Purkinje cells: first signal of neuronal damage in sudden fetal and infant death. J Clin Pathol (2016) 69(1):58-63. doi:10.1136/jclinpath-2015-202961
40. Lavezzi AM, Cappiello A, Termopoli V, Bonoldi E, Matturri L. Sudden infant death with area postrema lesion likely due to wrong use of insecticide. Pediatrics (2015) 136(4):e1039-42. doi:10.1542/peds.2015-0425

41. Lavezzi AM, Cappiello A, Pusiol T, Corna MF, Termopoli V, Matturri L. Pesticide exposure during pregnancy, like nicotine, affects the brainstem alpha7 nicotinic acetylcholine receptor expression, increasing the risk of sudden unexplained perinatal death. J Neurol Sci (2015) 348(1-2):94-100. doi:10.1016/j.jns.2014.11.014

42. Lavezzi AM, Corna MF, Repetti ML, Matturri L. Cerebellar Purkinje cell vulnerability to prenatal nicotine exposure in sudden unexplained perinatal death. Folia Neuropathol (2013) 51(4):290-301. doi:10.5114/fn.2013.39718

43. Lavezzi AM, Corna MF, Matturri L. Neuronal nuclear antigen (NeuN): a useful marker of neuronal immaturity in sudden unexplained perinatal death. J Neurol Sci (2013) 329(1-2):45-50. doi:10.1016/j.jns.2013.03.012

44. Lavezzi AM, Alfonsi G, Matturri L. Pathophysiology of the human locus coeruleus complex in fetal/neonatal sudden unexplained death. Neurol Res (2013) 35(1):44-53. doi:10.1179/1743132812Y.0000000108

45. Lavezzi AM, Matturri L. Neuroanatomical dysmorphology of the medial superior olivary nucleus in sudden fetal and infant death. Front Hum Neurosci (2012) 6:322. doi:10.3389/fnhum.2012.00322

46. Lavezzi AM, Weese-Mayer DE, Yu MY, Jennings LJ, Corna MF, Casale V, et al. Developmental alterations of the respiratory human retrotrapezoid nucleus in sudden unexplained fetal and infant death. Auton Neurosci (2012) 170(1-2):12-9. doi:10.1016/j.autneu.2012.06.005

47. Lavezzi AM, Matturri L, Del Corno G, Johanson CE. Vulnerability of fourth ventricle choroid plexus in sudden unexplained fetal and infant death syndromes related to smoking mothers. Int J Dev Neurosci (2013) 31(5):319-27. doi:10.1016/j.ijdevneu.2013.04.006

48. Lavezzi AM, Mehboob R, Matturri L. Developmental alterations of the spinal trigeminal nucleus disclosed by substance $\mathrm{P}$ immunohistochemistry in fetal and infant sudden unexplained deaths. Neuropathology (2011) 31(4):405-13. doi:10.1111/j.1440-1789.2010.01190.x

49. Lavezzi AM, Corna MF, Mehboob R, Matturri L. Neuropathology of the intermediolateral nucleus of the spinal cord in sudden unexplained perinatal and infant death. Int JDev Neurosci (2010) 28(2):133-8. doi:10.1016/j. ijdevneu.2010.01.001

50. Lavezzi AM, Corna M, Matturri L, Santoro F. Neuropathology of the GuillainMollaret triangle (Dentato-Rubro-Olivary Network) in Sudden Unexplained Perinatal Death and SIDS. Open Neurol J (2009) 3:48-53. doi:10.2174/18742 05X00903010048

51. Lavezzi AM, Corna M, Mingrone R, Matturri L. Study of the human hypoglossal nucleus: normal development and morpho-functional alterations in sudden unexplained late fetal and infant death. Brain Dev (2010) 32(4):275-84. doi:10.1016/j.braindev.2009.05.006

52. Lavezzi AM, Casale V, Oneda R, Weese-Mayer DE, Matturri L. Sudden infant death syndrome and sudden intrauterine unexplained death: correlation between hypoplasia of raphe nuclei and serotonin transporter gene promoter polymorphism. Pediatr Res (2009) 66(1):22-7. doi:10.1203/ PDR.0b013e3181a7bb73

53. Lavezzi AM, Matturri L. Functional neuroanatomy of the human pre-Botzinger complex with particular reference to sudden unexplained perinatal and infant death. Neuropathology (2008) 28(1):10-6. doi:10.1111/j.1440-1789.2007.00824.x

54. Lee BH, Kim YK. The roles of BDNF in the pathophysiology of major depression and in antidepressant treatment. Psychiatry Investig (2010) 7(4):231-5. doi:10.4306/pi.2010.7.4.231

55. Mehler MF, Purpura DP. Autism, fever, epigenetics and the locus coeruleus. Brain Res Rev (2009) 59(2):388-92. doi:10.1016/j.brainresrev.2008.11.001

56. Bouret S, Sara SJ. Locus coeruleus. Scholarpedia (2010) 5(3):2845. doi:10.4249/ scholarpedia. 2845

57. Kandel ER, Schwartz JH, Jessell TM. Principles of Neural Science. 4th ed. New York: McGraw Hill (2000). p. 591-624.

58. Guyenet PG, Stornetta RL, Abbott SB, Depuy SD, Kanbar R. The retrotrapezoid nucleus and breathing. Adv Exp Med Biol (2012) 758:115-22. doi:10.1007/978-94-007-4584-1_16

59. Paxinos G. The Mouse Brain in Stereotax Coordinates. 2nd ed. London: Gulf Professional Publishing (2004).

60. KahleW,FrotscherM. Taschenatlasanatomie:3Nervensystem undSinnesorgane. Stuttgart: Thiene Publishers (2005). p. 106-7. doi:10.1055/b-002-43897 
61. Powley TL. Central control of autonomic functions: The organization of the autonomic nervous system. In: Squire LR, Berg D, Bloom FE, du Lac S, Ghosh A, Spitzer NC, editors. Fundamental Neuroscience (Fourth Edition). San Diego: Academic Press (2013). p. 729-47.

62. Fatouleh R, Macefield VG. Respiratory modulation of muscle sympathetic nerve activity is not increased in essential hypertension or chronic obstructive pulmonary disease. J Physiol (2011) 589(Pt 20):4997-5006. doi:10.1113/ jphysiol.2011.210534

63. Murdoch S, Shah P, Jampana R. The Guillain-Mollaret triangle in action. Pract Neurol (2016) 16(3):243-6. doi:10.1136/practneurol-2015-001142

64. Fitzgerald MJT, Gruener G, MtUi E. Clinical Neuroanatomy and Neuroscience. 6th ed. Edinburgh: Saunders/Elsevier (2012). 216 p.

65. Withington-Wray DJ, Mifflin SW, Spyer KM. Intracellular analysis of respiratory-modulated hypoglossal motoneurons in the cat. Neuroscience (1988) 25(3):1041-51. doi:10.1016/0306-4522(88)90057-7

66. Roda F, Gestreau C, Bianchi AL. Discharge patterns of hypoglossal motoneurons during fictive breathing, coughing, and swallowing. J Neurophysiol (2002) 87(4):1703-11. doi:10.1152/jn.00347.2001

67. Briley M, Moret C. Neurobiological mechanisms involved in antidepressant therapies. Clin Neuropharmacol (1993) 16(5):387-400. doi:10.1097/ 00002826-199310000-00002

68. Smith JC, Abdala AP, Koizumi H, Rybak IA, Paton JF. Spatial and functional architecture of the mammalian brain stem respiratory network: a hierarchy of three oscillatory mechanisms. J Neurophysiol (2007) 98(6): 3370-87. doi:10.1152/jn.00985.2007

69. Davson H, Seegal MB. The return of the cerebrospinal fluid to the blood: the drainage mechanism. In: Physiology of CSF and Blood-Brain Barriers Boca Raton, FL: CRC Press, Taylor and Francis group (1996). p. 489-523.

70. Gressens P, Laudenbach V, Marret S. [Mechanisms of action of tobacco smoke on the developing brain]. J Gynecol Obstet Biol Reprod (Paris) (2003) 32(1 Suppl):1S30-2. [Article in French].

71. Roncati L, Pusiol T, Piscioli F, Lavezzi AM. Neurodevelopmental disorders and pesticide exposure: the northeastern Italian experience. Arch Toxicol (2017) 91(2):603-4. doi:10.1007/s00204-016-1920-7

Conflict of Interest Statement: The authors declare that the research was conducted in the absence of any commercial or financial relationships that could be construed as a potential conflict of interest.

Copyright (c) 2017 Mehboob, Kabir, Ahmed and Ahmad. This is an open-access article distributed under the terms of the Creative Commons Attribution License (CC BY). The use, distribution or reproduction in other forums is permitted, provided the original author(s) or licensor are credited and that the original publication in this journal is cited, in accordance with accepted academic practice. No use, distribution or reproduction is permitted which does not comply with these terms. 